\title{
A review of augmented reality in educational applications
}

\author{
Zainab H. Majeed* and Huda A. Ali \\ Assistant Lecturer, Department of Computer Science, University of Basrah, Iraq
}

Received: 28-November-2019; Revised: 11-January-2020; Accepted: 18-January-2020

(C)2020 Zainab H. Majeed and Huda A. Ali. This is an open access article distributed under the Creative Commons Attribution (CC BY) License, which permits unrestricted use, distribution, and reproduction in any medium, provided the original work is properly cited.

\begin{abstract}
In education, augmented reality (AR) provides a better user experience due to its features of displaying $3 D$ virtual information and interaction. Thus, many scholars have been attracted to developing this technology in their research. However, there are different types of AR technology represented in the educational environment. Therefore, the impact of using this technology in research may differ from one type to another. This paper provides an overview of AR technology in the educational environment. It investigates articles from three journals over three years (2017-2019). The paper is structured around three aims: first, to identify the type of AR used in each reviewed article; second, to extract the benefits of using AR technology, according to each type; and third, to specify the learning subject regarding each AR type. The review's significant findings showed that "user satisfaction" is the most frequently mentioned positive impact of integrating AR in education. It is also mentioned in all AR types.
\end{abstract}

\section{Keywords}

Augmented reality, AR, Educational applications.

\section{Introduction}

Augmented reality (AR) is a technology in which the real world is augmented by computer-generated content like text, images, and videos [1]. It has three main characteristics: combination of the real world and virtual elements, interaction with the user in realtime, and being registered in a 3D space [2]. Moreover, it offers freedom and new experiences to the users by allowing them to move a $3 \mathrm{D}$ virtual image and view it from any point just as with a real object [1-3]. Therefore, AR technology has been adopted in various research areas, such as ecommerce, travel, marketing, and education.

In the education sector, the use of AR technology produces rich learning experiences, enhances skills and knowledge, and improves collaborative learning [4]. This has encouraged researchers to integrate this technology into fields like biology, chemistry, mathematics, medicine, history, engineering etc. [5]. They examine the potential of AR technology and its effectiveness on the learning experience, or they make a comparison with other traditional learning methods.

*Author for correspondence
However, researchers have used different types of AR to achieve their goals. According to Yuen et al. [1], there are five types of AR applications: discovery-based learning (DBL), object modeling (OM), AR books, game-based learning (GBL), and skills training. Thus, learning effects may differ according to each type. Furthermore, each type could be used more in some specific disciplines than in others.

The objective of this review paper is to present an overview of previous studies that have integrated AR technology for learning purposes. It covers three journals and a period of three years (2017-2019). The paper aims to assign the benefits of using AR technology regarding its type. Furthermore, it explores the learning subject for each reviewed study to find out which learning subjects are most used for each AR type. The literature review questions are as follows:

RQ1: What type of AR application is used in the reviewed paper?

RQ2: What are the benefits of AR according to each type?

RQ3: What learning subjects are commonly used for each AR type? 
To answer these questions, the authors conducted this literature review, which is structured into five sections. First, it presents an introduction to AR technology and the research questions. Nest, it provides the five types of AR technology in the education environment. Then, it offers a comprehensive explanation of the literature analysis. The next section discusses the review paper's findings. Finally, it offers a conclusion based on the review.

\section{Types of augmented reality applications in educational environments}

Presenting AR technology in applications can differ from one study to another. Yuen et al. [1] classified AR educational applications into five types as follows:

\section{Discovery-Based Learning (DBL)}

These AR applications provide their users with additional information about a real-world place while considering the object of interest. Such AR applications are usually used in museums and astronomical education, and at historical sites, as they bring more excitement to these places. Different techniques are used in DBL applications, such as facial recognition to display certain pre-approved information about a person or object recognition to view information about real world items, for example, prices on items while shopping.

\section{Object-Modeling (OM)}

These AR applications utilize model objects to allow learners to visualize how a given item would look from different viewpoints. In addition, OM, AR applications allow learners to explore the physical properties and execute interactions between objects. For example, when the user uses the mobile webcam to record a simple sketch on paper, the 3D model will be generated. This can be rotated or changed in color, style, and transparency to give the learner a range of views and to explore their ideas in greater depth. Such applications are used in disciplines like architectural education and human anatomy.

\section{AR Books}

AR books close the gap between digital and physical learning [1]. They are books that offer 3D virtual presentations and an interactive experience for learners. AR books come with special devices, such as special glasses that are worn by users to display $3 \mathrm{D}$ characters that seem to leap from each page of the book.

\section{Game-Based Learning (GBL)}

Recently, video games have become powerful tools in the educational environment [6]. Therefore, educators often use games to simplify complex concepts for students. With AR technology, virtual information that is augmented with games could provide new and powerful ways of learning about the real world.

There are many ways to represent AR in games [1]: games use marker technology where a flat game board or map displays in a 3D shape that was once viewed using a mobile device. These kinds of AR games are usually used in disciplines like archaeology, history, anthropology, or geography. Another type of AR game allows users to create virtual objects or people and then apply them to a specific location in the real world. Such AR games also offer interaction with these objects.

\section{Skills Training}

This is an area where AR applications have a strong potential because of the virtual context they provide. They are used to train individuals in specific tasks, such as hardware mechanics in the military or airplane maintenance. For example, in airplane maintenance, they display each step in a repair, identify the tools needed, and show the textual instructions.

\section{Literature review}

A three-phase process was applied to achieve the review goals. The first phase was collecting the target data, the second phase was analyzing the collected data, and the final phase was mapping the results to give answers to the research questions.

\subsection{Data collection}

Google Scholar top publications were the source of this literature review. Journals were selected based on the h5-index for the category "Engineering \& computer science" then the sub-category "Educational Technology". The top five listed journals chosen for this review were the following: "Computers and Education" with h5-index 94 and listed first, " British Journal of Educational Technology" with h5-index 56 and listed second, "The International Review of Research in Open and Distributed Learning" with h5-index 54 and listed third, "The Internet and Higher Education" with h5index 50 and listed fourth, and "Journal of Educational Technology \& Society" with h5-index 49 and listed fifth in Google Scholar top publications. Then, each journal was analyzed over a period of 
three years (2017-2019) to find the articles related to the review's main keyword "AR" technology. After analysis, two journals, namely, "The International Review of Research in Open and Distributed Learning" and "The Internet and Higher Education", were discarded since over the period for the research, they did not contain any articles related to AR technology. Therefore, the literature review covers the three journals that are shown in Table 1.
Over the three years (2017-2019), 1,160 articles were found in the three mentioned journals. These articles were filtered to identify the articles that were based on AR technology. After this process, the number of articles that could be used for the analysis phase dropped to 16 articles. Figure 1 shows the process of collecting the review data.

Table 1 list of the considered journals and number of articles published over three years (2017-2018)

\begin{tabular}{|c|c|c|c|c|c|c|c|c|c|}
\hline \multirow[t]{2}{*}{ Journal } & \multirow[t]{2}{*}{ Publisher } & \multirow[t]{2}{*}{$\begin{array}{l}\text { H5- } \\
\text { index }\end{array}$} & \multicolumn{3}{|c|}{$\begin{array}{l}\text { Number of published } \\
\text { articles }\end{array}$} & \multicolumn{3}{|c|}{$\begin{array}{l}\text { Number of published } \\
\text { articles related to AR }\end{array}$} & \multirow[t]{2}{*}{ Total } \\
\hline & & & 2017 & 2018 & 2019 & 2017 & 2018 & 2019 & \\
\hline $\begin{array}{l}\text { Computer \& } \\
\text { education }\end{array}$ & Elsevier & 94 & 162 & 215 & 198 & 4 & 2 & 2 & 8 \\
\hline $\begin{array}{l}\text { British Journal of } \\
\text { Educational } \\
\text { Technology }\end{array}$ & $\begin{array}{l}\text { British } \quad \text { Educational } \\
\text { Research Association }\end{array}$ & 56 & 107 & 80 & 203 & 2 & 1 & 1 & 4 \\
\hline $\begin{array}{l}\text { Educational } \\
\text { Technology } \\
\text { Society }\end{array}$ & $\begin{array}{ll}\begin{array}{l}\text { International } \\
\text { Educational } \\
\text { and Society }\end{array} & \begin{array}{l}\text { Forum of } \\
\text { Technology }\end{array} \\
\end{array}$ & 49 & 92 & 83 & 20 & 2 & 1 & 1 & 4 \\
\hline Total & & & & & & 8 & 4 & 4 & 16 \\
\hline
\end{tabular}
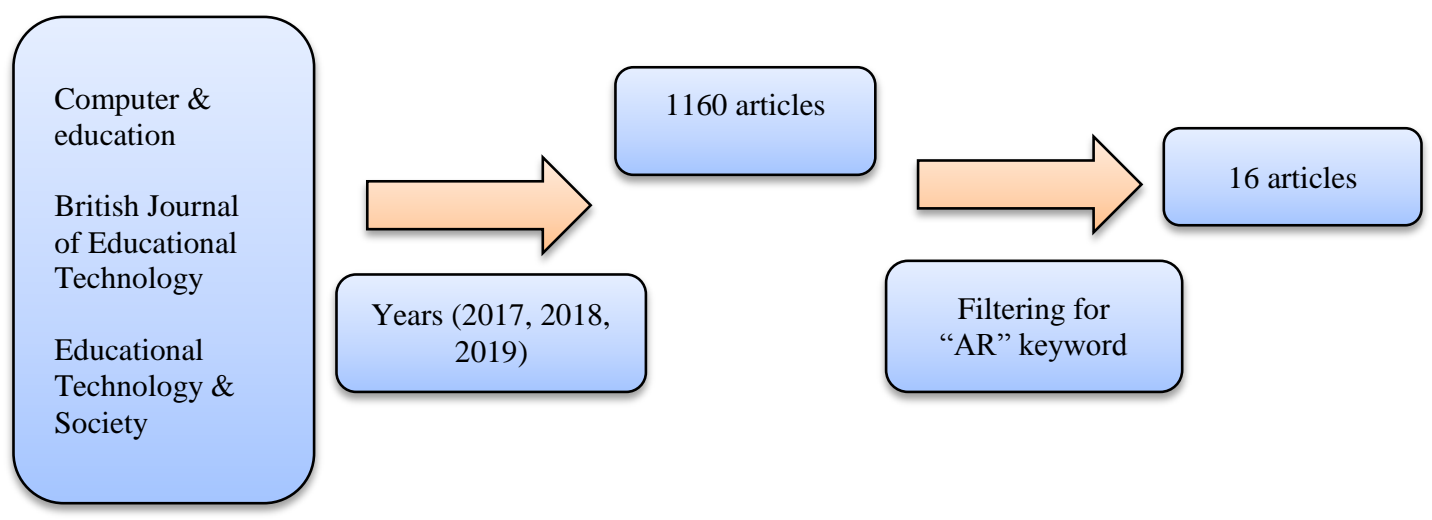

Figure 1 The process of data collection

\subsection{Data coding and analysis}

Sixteen articles were identified during the data collection phase. They passed through the analysis steps as demonstrated in Figure 2.

First, based on the definitions suggested by Yuen et al. [1], the authors identified the type of AR that was used in each study. Both authors worked separately to determine the types of AR in each article (RQ1). Then they compared their results. If they had a different opinion, a discussion was held to reach an agreement. The AR type was mostly decided by reading the method, design, and experiment sections of the reviewed studies and examining the figures included.
To determine the AR type, the authors collected information regarding the benefits of using AR mentioned in each article (RQ2). Such benefits were usually recognized by reading through the results, findings, discussion, and evaluation sections. Similar benefits were grouped and clustered into categories and subcategories according to the method suggested by [7] and used in [8].

The next task was to find an answer to the third research question (RQ3). While reading the abstract, introduction, method, and results of the articles, the authors were able to identify the learning subject of each article. 


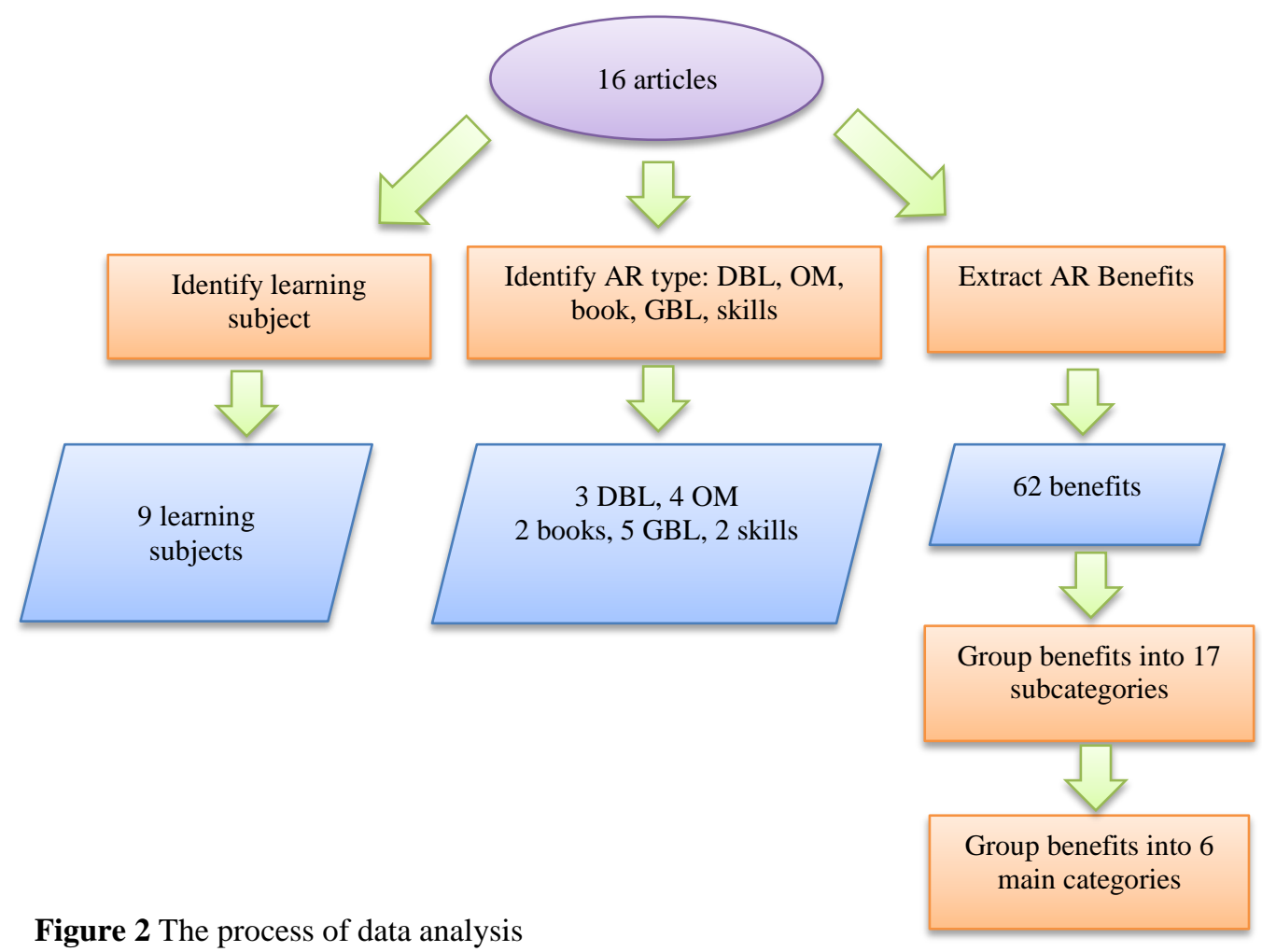

Figure 2 The process of data analysis

\subsection{Mapping of reviewed studies}

This section presents the mapping of the 16 selected articles. Three tables were structured to answer the three research questions. Table 2 shows the five types of AR in the educational environment and indicates which of the reviewed articles belong to each type. This table answers RQ1: What type of AR application is used in the reviewed paper?
The second table is the assignment of benefits addressed in each article according to AR type. This table answers RQ2: What are the benefits of AR according to each type?

The last table displays the reviewed articles regarding the subject. It answers RQ3: What learning subjects are commonly used for each AR type?

Table 2 The distribution of reviewed articles regarding each AR type

\begin{tabular}{lll}
\hline No. & AR type & Articles \\
\hline 1 & DBL & {$[9-11]$} \\
\hline 2 & OM & {$[12-15]$} \\
\hline 3 & AR book & {$[16-18]$} \\
\hline 4 & GBL & {$[19-22]$} \\
\hline 5 & Skills training & {$[23,24]$} \\
\hline
\end{tabular}

Table 3 The benefits of integration AR technology regarding to each AR type

\begin{tabular}{|c|c|c|c|c|c|c|c|}
\hline No. & Effect category & Subcategory & DBL & OM & Book & GBL & skills \\
\hline \multirow{5}{*}{1} & \multirow{5}{*}{$\begin{array}{l}\text { User } \\
\text { mind }\end{array}$} & Motivation & {$[9,11]$} & {$[13,15]$} & [17] & {$[22]$} & - \\
\hline & & Engagement & - & - & [18] & {$[21,22]$} & [23] \\
\hline & & Concentration & [9] & - & - & - & - \\
\hline & & Satisfaction & $\begin{array}{l}{[9,10]} \\
{[11]}\end{array}$ & {$[12,15]$} & {$[17,16]$} & {$[21,22]$} & [23] \\
\hline & & Attention & - & - & (17) & - & - \\
\hline \multirow[t]{2}{*}{2} & \multirow{2}{*}{$\begin{array}{l}\text { Teaching } \\
\text { concepts }\end{array}$} & $\begin{array}{l}\text { Student-centered } \\
\text { learning }\end{array}$ & [9] & [12] & - & - & - \\
\hline & & Collaborative & - & [13] & - & [21] & - \\
\hline
\end{tabular}


Zainab H. Majeed and Huda A. Ali.

\begin{tabular}{|c|c|c|c|c|c|c|c|}
\hline No. & Effect category & Subcategory & DBL & OM & Book & GBL & skills \\
\hline & & learning & & & & & \\
\hline \multirow{3}{*}{3} & \multirow{3}{*}{ Presentation } & Visual appealing & {$[10,11]$} & - & [16] & [21] & - \\
\hline & & Visual aids & {$[9,10]$} & [12] & {$[16]$} & {$[21]$} & {$[23]$} \\
\hline & & Interactivity & {$[10,11]$} & {$[12,13]$} & {$[16,18]$} & - & [23] \\
\hline \multirow{3}{*}{4} & \multirow{3}{*}{$\begin{array}{l}\text { Learning } \\
\text { achievements }\end{array}$} & $\begin{array}{l}\text { Learning is faster } \\
\text { and easier }\end{array}$ & {$[10]$} & [12] & - & [19] & [24] \\
\hline & & $\begin{array}{l}\text { More learning } \\
\text { gains }\end{array}$ & {$[11]$} & [15] & [17] & {$[19-21]$} & [23] \\
\hline & & $\begin{array}{l}\text { Critical thinking } \\
\text { and analysis }\end{array}$ & - & {$[13,15]$} & - & - & - \\
\hline \multirow{2}{*}{5} & \multirow{2}{*}{ Stat of memory } & $\begin{array}{l}\text { Preserving } \\
\text { information }\end{array}$ & - & {$[12,15]$} & - & (20) & - \\
\hline & & $\begin{array}{l}\text { Reduce mental } \\
\text { load }\end{array}$ & [9] & - & [17] & - & - \\
\hline \multirow[t]{2}{*}{6} & Reduce cost & Reduce cost & - & - & - & - & (23) \\
\hline & Total & & 16 & 15 & 11 & 13 & 7 \\
\hline
\end{tabular}

Table 4 Learning subjects of AR technology regarding each AR type

\begin{tabular}{|c|c|c|c|c|c|c|}
\hline Learning subject & Sub-field & DBL & OM & AR book & GBL & Skill \\
\hline \multirow{6}{*}{ Natural science } & Astronomy & [9] & - & - & - & - \\
\hline & Physics & - & {$[12,15]$} & - & - & - \\
\hline & Geology & {$[11]$} & - & - & - & - \\
\hline & engineering & - & - & - & - & {$[24,23]$} \\
\hline & Math & - & - & [18] & - & - \\
\hline & unspecified & & {$[13]$} & [17] & & - \\
\hline Literacy & & - & [14] & [16] & [19-21] & - \\
\hline History & & {$[10]$} & - & - & - & - \\
\hline Social life & & - & - & - & {$[22]$} & - \\
\hline
\end{tabular}

\section{Results and discussion}

This section reports the results gained from reviewing and analyzing 16 published articles that were related to $\mathrm{AR}$ in education.

4.1RQ1: What type of AR application is used in the reviewed paper?

Regarding the AR type used in each article, the authors identified four articles with the OM type. This number represents $25 \%$ of the total number of articles. The same number of articles was found in GBL (25\%) while both DBL and AR book had three articles each (18.75\% of each type). Skills training had the fewest articles; only two articles were found in this AR type $(12.5 \%$ of the total number of reviewed articles). Figure 3 shows the Distribution of articles regarding to AR type.

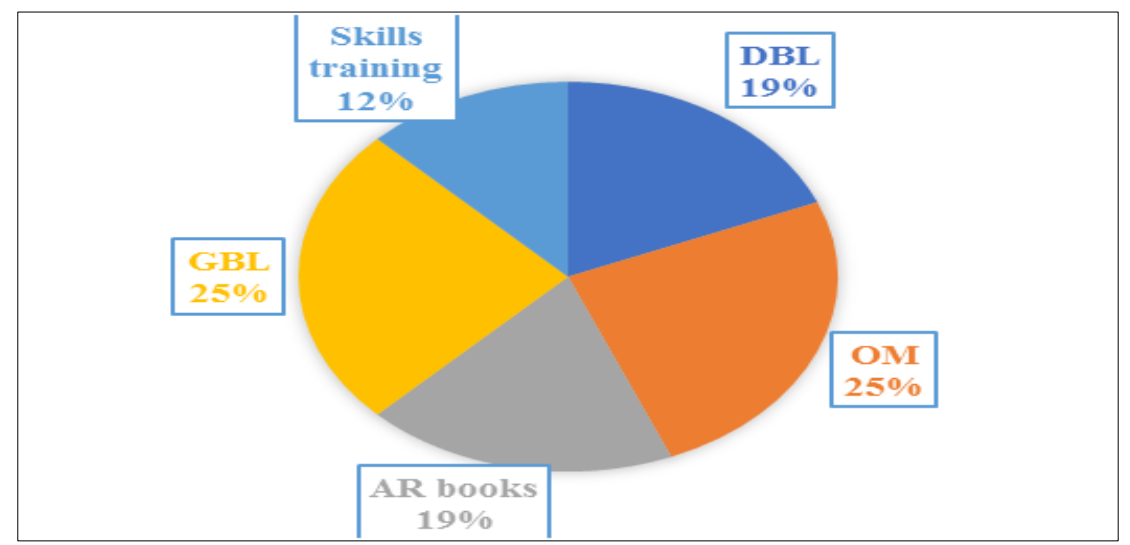

Figure 3 Distribution of articles regarding to AR type 
4.2RQ2: What are the benefits of AR according to each type?

Regarding the review's second question, from the 16 reviewed studies, a total of 62 positive benefits of integrating AR technology was identified. The benefits were classified into 16 subcategories and then clustered into groups under 6 main categories. The benefits addressed in each of the reviewed studies were assigned according to AR type as below:

\section{Discovery-based learning (DBL):}

This type of AR has the greatest number of positive effects of using this technology in education. Over three articles that adopted the concept of DBL, 16 benefits were identified. This number represents $25.8 \%$ of the total benefits. The DBL type recorded 6 benefits belonging to enhancing the user's state of mind, especially increasing the user's motivation, concentration, and satisfaction; for example, "They all self-report high levels of satisfaction in regards to the AR system" [11]. In the presentation category, the same number ( 6 benefits) was found. An example of presentation benefits is "We found out that the 3D presentation on the system satisfied the diverging learners' innovative need" [11]. DBL could also be useful for more learning gains and improving the state of the memory by reducing the mental load. However, there is no cost reduction in this DBL type. Quotations from articles include the following: "With the features of the AR system, learners can easily integrate virtual objects and real environments so as to decrease the mental load and improve their learning" [9], and "promote the interaction of students with contents for learning" [10].

\section{Object modeling (OM)}

This AR type has the second highest number of mentioned benefits; 15 benefits were recognized in 3 articles based on OM applications. This AR approach could enhance user motivation and satisfaction: "AR technology can be a potential and effective tool for activating students' positive emotions in the PBL process" [15]. OM also has positive effects on the teaching concepts in both student-centered learning and collaborative learning: "Learning is largely influenced by collaboration among peers while using the AR device" [12]. Two articles mentioned that OM enhanced presentation through visual aids and interactivity. Regarding learning achievements, four benefits were registered in this criterion: two belong to critical thinking and analyzing while faster and easier learning and learning gains have only one benefit each: "improved their learning motivation, critical thinking tendency" [15]. The final benefit of using the $\mathrm{OM}$ approach is the enhancement in preserving information, which is mentioned in two articles.

\section{AR books}

The authors found three articles that used AR books; 11 out of 62 effects were recorded in this type of AR technology. Similar to other types of AR approaches, AR books positively affected users' state of mind in terms of motivation, engagement, and satisfaction. However, the improvement of users' attention was identified only in this type of AR: "The augmented reality experimental group reported higher levels of attention" [17]. In addition, two articles reported that AR books present learning contents much better than traditional books: "ARPB are attractive and evocative for children, who perceive them as magic and more enjoyable than conventional books" [16]. More learning gains and less mental load were noticed in one of the reviewed studies: "Students learning with this approach made significant gains in their learning achievements and motivations compared to those learning sciences with conventional multimedia science learning; moreover, their perceptions of extraneous cognitive load were significantly reduced during the learning activity" [17].

\section{Game-based learning (GBL)}

AR games were applied in four studies. This type of AR has 13 benefits in total. Most of these benefits belong to the user's state of mind category with five benefits: "ARC helped students to be more engaged in learning" [21]. Using AR games in education achieved four benefits in learning, such as faster and easier learning (mentioned in one article), and more learning gains (mentioned in three articles): "Students using the self-directed or task-based AR educational game system had similar and high learning effectiveness" [20]. Visual appeal and visual aids are also effective in AR games. They were reported in one article: "All the students that played the ARC expressed that they liked the pictures and animations embedded in the game, and they believed that the multimedia could help them to understand tasks or texts" [22]. The same article mentioned that AR games obviously improved collaborative learning: "There were obvious improvements in the students' collaborative learning competency after the ARC game playing" [23]. Finally, GBL could enhance the state of memory, in particular, preserving information. This benefit was mentioned in one article. 


\section{Skills training}

Regarding AR skills training, seven benefits were identified in two articles. This means the skills training type had the fewest positive impacts. However, unlike the other AR types, skills training is the only type which achieves a reduction in the cost benefit: "The sensing, storage, computation, and communication (SSCC) capabilities of mobile devices are leveraged to relieve the need for laboratory-grade equipment, improving the costeffectiveness and portability of platforms to conduct hands-on laboratories" [24].
Regarding the learning subjects, literacy was the most common subject in the 16 reviewed articles: 5 articles focused on learning, writing, reading or vocabulary in different languages, and 3 of these articles were about GBL. The next preferred subjects were physics and engineering with two articles each. The physics subject was represented by the OM type whereas engineering was represented by skills training. Astronomy, history, and geology had one article each; all of these subjects were under DBL. Figure 4 shows the distribution of learning subjects in each AR type.

\subsection{RQ3: What learning subjects are commonly used for each AR type?}

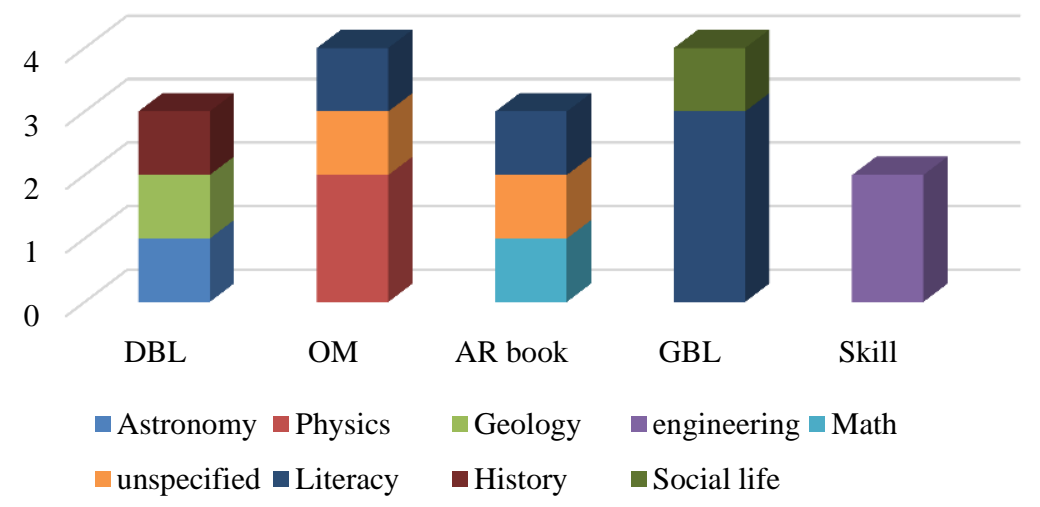

Figure 4 The distribution of learning subjects in each AR type

\section{Conclusion}

AR has great potential and many benefits in the education sector. It allows the learner to interact with virtual 3D objects and offers a better user experience. Therefore, many scholars have been interested in AR technology and have integrated it into their research. However, they have introduced this technology to the users in five different directions (discovery-based learning, object modeling, AR books, game-based learning, and skills training). They have also identified a number of benefits of using AR technology. This paper has presented a review of educational applications that are based on AR technology. It has reviewed and analyzed 16 articles from three journals and over a period of three years (2017-2018).

The results show that OM and GBL are equally the most frequently used AR type, whereas skills training is the least used type in the educational environment. Moreover, the findings report 62 benefits of using $\mathrm{AR}$ in education. These benefits were clustered into 26
16 unique ones and classified into their AR type. The classification showed that DBL has the most benefits while skills training has the fewest. However, reducing the cost was reported only in skills training. These findings could be useful for research into AR educational applications, as the benefits of using this technology may differ according to its type.

\section{Acknowledgment}

None.

\section{Conflicts of interest}

The authors have no conflicts of interest to declare.

\section{References}

[1] Yuen SC, Yaoyuneyong G, Johnson E. Augmented reality: an overview and five directions for $A R$ in education. Journal of Educational Technology Development and Exchange. 2011; 4(1):119-40.

[2] Azuma RT. A survey of augmented reality. Presence: Teleoperators \& Virtual Environments. 1997; 6(4):355-85. 
[3] Kesim M, Ozarslan Y. Augmented reality in education: current technologies and the potential for education. Procedia-Social and Behavioral Sciences. 2012; 47:297-302.

[4] Wu HK, Lee SW, Chang HY, Liang JC. Current status, opportunities and challenges of augmented reality in education. Computers \& Education. 2013; 62:41-9.

[5] Pantelić A, Vukovac DP. The development of educational augmented reality application: a practical approach. In international conference of education, research and innovation 2017.

[6] Diegmann P, Schmidt-Kraepelin M, Eynden S, Basten D. Benefits of augmented reality in educational environments-a systematic literature review. Benefits. 2015; 3(6): 1542-56.

[7] Jankowicz D. The easy guide to repertory grids. John wiley \& sons; 2005.

[8] https://www.talk-business.co.uk/2018/07/09/thebenefits-of-augmented-reality-in-education-andlearning-process/ . Accessed 23 October 2019.

[9] Liou HH, Yang SJ, Chen SY, Tarng W. The influences of the 2D image-based augmented reality and virtual reality on student learning. Journal of Educational Technology \& Society. 2017; 20(3):110-21.

[10] Joo-Nagata J, Abad FM, Giner JG, García-Peñalvo FJ. Augmented reality and pedestrian navigation through its implementation in m-learning and e-learning: evaluation of an educational program in chile. Computers \& Education. 2017; 111:1-7.

[11] Huang TC, Chen MY, Hsu WP. Do learning styles matter? motivating learners in an augmented geopark. Journal of Educational Technology \& Society. 2019; 22(1):70-81.

[12] Yoon S, Anderson E, Lin J, Elinich K. How augmented reality enables conceptual understanding of challenging science content. Journal of Educational Technology \& Society. 2017; 20(1):156-68.

[13] Chang SC, Hwang GJ. Impacts of an augmented reality-based flipped learning guiding approach on students' scientific project performance and perceptions. Computers \& Education. 2018; 125:22639.

[14] Rau PL, Zheng J, Guo Z, Li J. Speed reading on virtual reality and augmented reality. Computers \& Education. 2018; 125:240-5.

[15] Fidan M, Tuncel M. Integrating augmented reality into problem based learning: the effects on learning achievement and attitude in physics education. Computers \& Education. 2019; 142:103635.

[16] Yilmaz RM, Kucuk S, Goktas Y. Are augmented reality picture books magic or real for preschool children aged five to six? British Journal of Educational Technology. 2017; 48(3):824-41.
[17] Lai AF, Chen CH, Lee GY. An augmented realitybased learning approach to enhancing students' science reading performances from the perspective of the cognitive load theory. British Journal of Educational Technology. 2019; 50(1):232-47.

[18] Nadolny L. Interactive print: the design of cognitive tasks in blended augmented reality and print documents. British Journal of Educational Technology. 2017; 48(3):814-23.

[19] Wang YH. Exploring the effectiveness of integrating augmented reality-based materials to support writing activities. Computers \& Education. 2017; 113:162-76.

[20] Hsu TC. Learning english with augmented reality: do learning styles matter? Computers \& Education. 2017; 106:137-49.

[21] Wen Y. Chinese character composition game with the augment paper. International Forum of Educational Technology and Society. 2018; 21(3):132-45.

[22] Korozi M, Leonidis A, Ntoa S, Arampatzis D, Adami I, Antona M, et al. Designing an augmented tabletop game for children with cognitive disabilities: the "home game" case. British Journal of Educational Technology. 2018; 49(4):701-16.

[23] Frank JA, Kapila V. Mixed-reality learning environments: integrating mobile interfaces with laboratory test-beds. Computers \& Education. 2017; 110:88-104.

[24] Yip J, Wong SH, Yick KL, Chan K, Wong KH. Improving quality of teaching and learning in classes by using augmented reality video. Computers \& Education. 2019; 128:88-101.

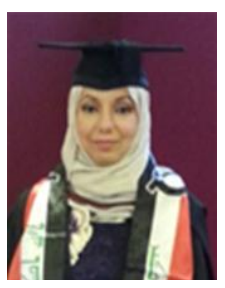

Zainab H. Majeed received the Bachelor degree in Computer Science from University of Basrah, Iraq, in 2006 and the Master degree in Computer Science (Advance Computer Science) from Swansea University, in 2015, UK. She is currently working as an Assistant Lecturer at University of Basrah, Iraq. Her research interests include Human Computer Interaction, Mobile Human Computer Interaction, and Software Engineering.

Email: alfayez.zainab@gmail.com

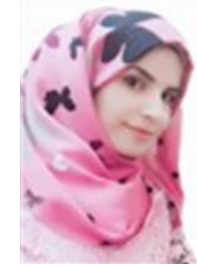

Huda A. Ali received the Bachelor degree in Computer Science from University of Basrah, Iraq, in 2007 and the Master degree in Computer Science (Natural Languages) from University of Basrah, Iraq. She is currently working as an Assistant Lecturer at the department of Computer Science, College of CS \& IT, University of Basrah, Iraq. Her research interests include Natural Languages and Machine Learning. 